\title{
Numerical Analysis of Heat Exchanger for Spray-Assisted Low-Temperature Desalination System
}

\author{
Amour Othman Muhunzi $\mathbb{D}^{1,2}$ Yusufu Abeid Chande Jande $\mathbb{D}^{1}{ }^{1}$ \\ and Revocatus Lazaro Machunda $\mathbb{D i D}^{3}$ \\ ${ }^{1}$ Department of Materials and Energy Sciences and Engineering, The Nelson Mandela African Institution of Science and Technology, \\ P.O. Box 447, Arusha, Tanzania \\ ${ }^{2}$ Department of Technical Services, The Government Agency for Tractors and Farm Machineries Services, P.O. Box 1064, \\ Zanzibar, Tanzania \\ ${ }^{3}$ Department of Environmental Sciences and Engineering, The Nelson Mandela African Institution of Science and Technology, \\ P.O. Box 447, Arusha, Tanzania
}

Correspondence should be addressed to Amour Othman Muhunzi; muhunzia@nm-aist.ac.tz

Received 18 April 2020; Revised 19 August 2020; Accepted 24 September 2020; Published 16 November 2020

Academic Editor: Ciro Aprea

Copyright (C) 2020 Amour Othman Muhunzi et al. This is an open access article distributed under the Creative Commons Attribution License, which permits unrestricted use, distribution, and reproduction in any medium, provided the original work is properly cited.

\begin{abstract}
A numerical study for heat exchanger for spray-assisted low-temperature desalination system is presented for an existing lowtemperature desalination unit at Arusha Technical College. This is aimed at recognizing the effect of mass flow and physical parameters like tube layout (diameter and length) on the overall heat transferred and the pressure drop in the shell-and-tube heat exchanger (STHX), as well as the impact of these parameters on the heat transfer coefficient and the overdesign of the STHX. Also, the study provides a suitable mathematical model for the replacement of the current condensation unit which tends to reduce energy consumption by reducing some of the electrical components in the system. A Math CAD model was developed using the Delaware method to obtain the mentioned parameters. The results show that at $0.8 \mathrm{~kg} / \mathrm{s}$ flow rate a maximum heat transfer coefficient of $23212 \mathrm{~W} / \mathrm{m}^{2} \mathrm{~K}$ is achieved in a minimum diameter of 10 mm within a maximum tube length of $1000 \mathrm{~mm}$ heat exchanger and the pressure drop seems to be very low in a range of $0.328-0.957 \mathrm{~Pa}$ from all configurations. The configuration with $1000 \mathrm{~mm}$ tube length and $10 \mathrm{~mm}$ diameter performed well on the mass flow of $0.3 \mathrm{~kg} / \mathrm{s}-0.8 \mathrm{~kg} / \mathrm{s}$ by providing a suitable overall heat transfer coefficient of $2306-2539 \mathrm{~W} / \mathrm{m}^{2} \mathrm{~K}$, while 12.8 is a maximum overdesign coefficient achieved on $0.8 \mathrm{~kg} / \mathrm{s}$ mass flow. The study results show the possibility of using STHX instead of the current condensation unit in implementing a proposed system layout with the minimum effect of energy consumption.
\end{abstract}

\section{Introduction}

The present society demands the efficient utilization of energy and at the same time reducing environmental impact to contribute to sustainable economic development. The increase of freshwater demand is mainly caused by the development of world industries and human population growth, while potable water is one of the key resources for the existence of human beings [1]. Desalination of brackish or seawater is an important approach to solve the water resource dearth. We may categorize the desalination process as thermal and nonthermal based on energy consumption [2].

Spray-assisted low-temperature phase-change desalination technique is the thermal-based method that makes no boundary upon heat and mass transfer mechanism and eliminates the contribution of mechanical energy input [3]. This technology comprises two main units to reach the freshwater, namely, evaporation unit and condensation unit [4]. Fortunately, solar energy can either be used directly or indirectly in supplying thermal energy to an evaporation unit as used in vaporization of liquid 
into vapor and cause steam formation [5]. However, the heat exchange process occurs in the condensation unit by exchanging steam temperature with that of cooling media (gas or liquid) and condensing the steam into liquid freshwater [6].

Literature shows some of the experimental and numerical studies done by some researchers concerned with the condensation unit in different desalination systems. Alsadaie and Mujtaba [7] through the multistage flash (MSF) desalination developed a dynamic fouling model of the heat exchanger, reaction and diffusion mechanisms were included to investigate the effect of surface temperature and flow velocity, and the fouling results made a clear agreement with the literature on current studies. The cryogenic refrigeration unit embedded with multieffect desalination unit hybrid system was designed by Ghorbani et al. [8] which analyzed the thermos-economic.

In adsorption desalination, Elsayed et al. [9] used an aluminum fumarate metal-organic framework in experimental observation of cooling water desorption, adsorption, and condensation. Olkis et al. [10] analyzed the performance of an adsorption heat transformer through the usage of benchmarking material silica gel in the production of freshwater together with the cooling process as done by Thu et al. [11] and achieved a performance ratio of 0.60 at the inlet temperature of $80^{\circ} \mathrm{C}$. Also, silica gel was proposed by Rezk et al. [12] to be employed in solar-assisted adsorption desalination cooling for the performance maximization; the results show an improvement of $70 \%$ increase in specific cooling power, 0.961 coefficient of performance, and $6.9 \mathrm{~m}^{3} /$ day/ton specific daily water production.

Another study was done by Woo et al. [13] on a silica gelbased adsorption cooling cum desalination system concerned with the performance effect, operating pressure, and brine concentration. Towards eco-friendliness, David et al. [14] recovered the waste heat through the method of evaporative condenser cum thermal desalination. An experimental study was conducted by Rabhi et al. [15] on the external condenser and pin fin absorber from a modified solar still; the evaluation was based on the performance of water production and the thermal behavior.

Chandrakanth et al. [16] computed the tube-side pressure drop and heat transfer area respective in the optimization of the shell and tube condenser process parameters and geometric used in thermal desalination plants. The optimum pressure drop vs. heat transfer area was concluded from the second law analysis to overcome the trade-off in between. Via stoichiometric process in the spray flash desalination system, a water level model for after condenser was constructed by Matsuda et al. [17]; the results show the proper model that could improve the system behavior.

From the above literature, the flash evaporator has been reported from many theoretical and experimental studies as an essential unit in the low-temperature desalination technology. But there is no specific study that discusses the condensation unit on flash evaporation desalination technology. Moreover, currently, there is an existing lowtemperature desalination unit at Arusha Technical College
(ATC), which uses more energy at the condensation unit. Thus, this paper focuses on a heat exchanger design for spray-assisted low-temperature desalination, whereby the pressure drop, heat transfer coefficient, overall heat transfer coefficient, oversurface, and overdesign are the main concern. The heat exchanger is designed to reduce the level of energy consumption, allowing for a smooth working environment of the desalination unit.

\section{Modification of Existing System Configuration}

Figure 1 shows a schematic of the current layout with several electric components, namely, blower, feed pump, filter with a suction fan, cooling water circulation pump, and condenser with a suction fan. These components make a high level of energy intensity. Here, saline water from the source chamber is pumped into the flash chamber via nozzles. The sprayed flash occurs and the small droplets absorb the thermal energy in the flash chamber to form steam. Steam is escaping the chamber by passing between the chamber's walls, sucked through filter suction fan directly to the filter, then sucked by condenser suction fan and condensed, and finally stored as freshwater in a distillate reservoir. The steam is condensed when the cold water is circulated in the condenser from the water circulator tank via a second feed pump. At the same time, the condenser suction fan sucks the steam from the filter to speed up the process in which much steam is allowed to escape into the atmosphere. Both condenser and filter suction fans increase the amount of energy consumption on the system.

Figure 2 shows a schematic of a proposed layout that remains with the blower and the feed pump only which may alleviate the energy consumption through the implementation of the heat exchanger as a condensation unit. Now, source water from the source chamber is pumped to evacuated tube collector through the heat exchanger then fed to a flash chamber via nozzles. As usual, the sprayed flash occurs and absorbs the thermal energy in the flash chamber to form steam. Steam escapes the chamber by passing at the top, condensed by exchanging heat with cold water from the source at the heat exchanger, and stored as a freshwater. The blower is embedded with a flash chamber to increase temperature and relative humidity [18]. The heat exchanger acts as a condenser and at the same time becomes a preheater for the incoming cold water. The evacuated tube collector (also a preheater) raises further the temperature of the feed water before it is fed into the flash chamber.

\section{Heat Exchanger}

The heat exchange process takes place between two or more channels at different temperatures when fluids of the channels exchange their temperature by passing through a heat exchanger [19]. The heat exchanger is a piece of equipment that permits heat transfer and often goes together with mass transfer [20]. The equipment has been used in various industries including processing industries, power plants, and many other industries [21]. Among the several heat exchanger 


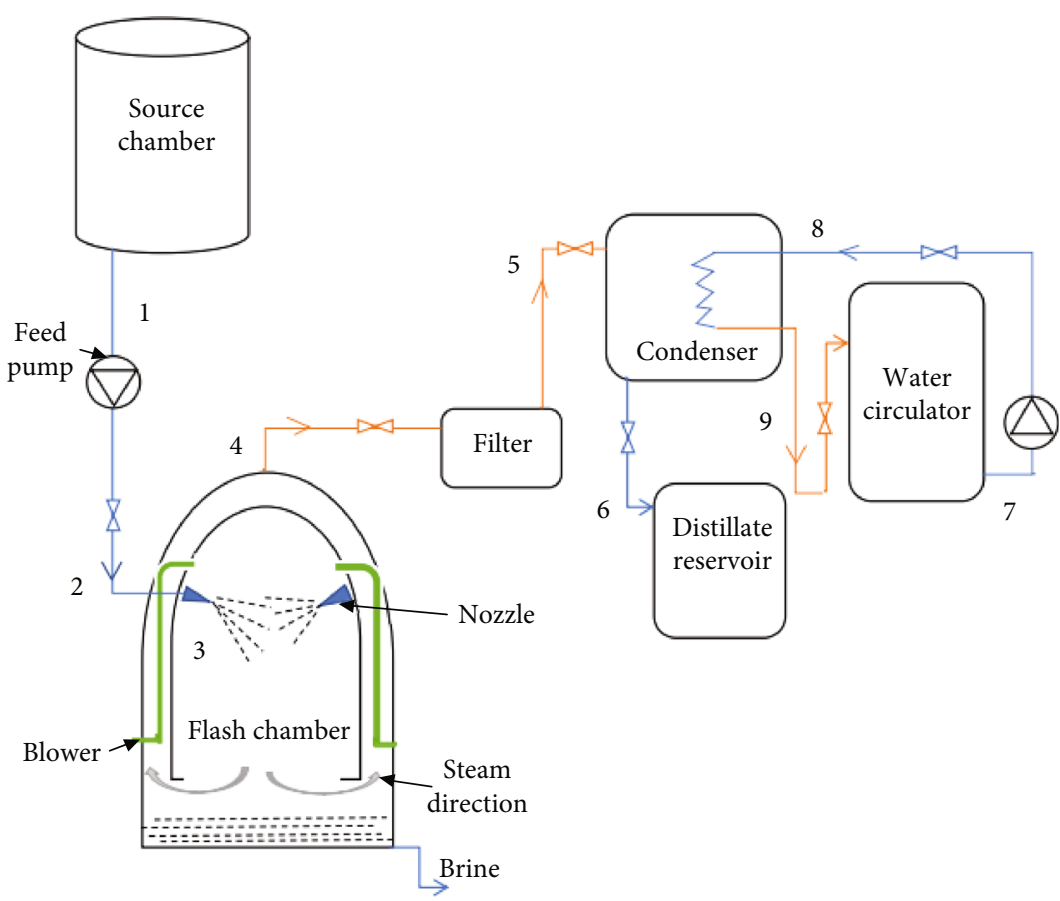

FIgURE 1: The current layout of spray flash evaporation system.

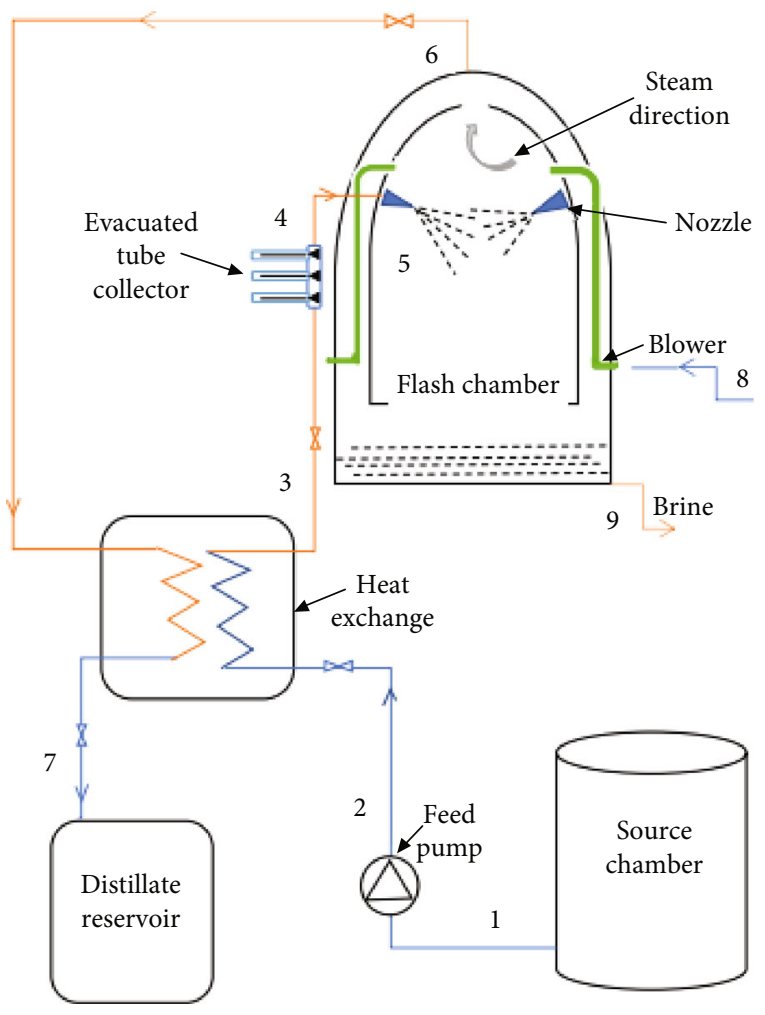

Figure 2: Proposed layout of spray flash evaporation system.

models, shell-and-tube heat exchangers (STHX) are the best [22] and widely used [23]. Also, it can be constructed easily in an extensive range of sizes compared to other categories [24]. A model of the shell-and-tube heat exchanger is shown in Figure 3(b).

\section{Methodology}

Thermal conductivity, density, viscosity, and specific heat capacity of the cold and hot fluid stream were among the factors estimated in the primary stage in the STHX design as can be seen in Table 1, taken from the existing evaporator which appeared in Figure 3(a). Double shell passes were taken into account, and a triangular pitch of 1.25 space between tube to tube centers was considered for the analysis. A single segmental baffle was chosen for ease of maintenance and high thermal features. U-tube (tube sheet) was used to permit a distinction of thermal expansion. Moreover, the outlet temperatures 29 and $28^{\circ} \mathrm{C}\left(t_{7}\right.$ and $\left.t_{3}\right)$ for steam and water, respectively, were assumed to control the output and easy computation as shown in Figure 3(b).

4.1. Thermal Design. The temperature difference on the tube side or that of shell side was used to define the sensible heat transfer rate of a heat exchanger. The cold and hot fluid stream loads were calculated using equation (1) as described by [25]

$$
Q=\dot{m}_{\mathrm{f}} \mathrm{Cp}_{\mathrm{f}}\left(t_{3}-t_{2}\right)=\dot{m}_{\mathrm{g}} \mathrm{Cp}_{\mathrm{g}}\left(t_{6}-t_{7}\right)
$$

where $\dot{m}_{\mathrm{g}}$ and $\dot{m}_{\mathrm{f}}$ are mass flow rate of steam and water, respectively, $Q$ is heat transfer rate, $C p_{g}$ and $C p_{f}$ are specific heat capacity of steam and water, respectively, $t_{3}$ and $t_{2}$ are outlet and inlet temperature of the water, and $t_{7}$ and $t_{6}$ are outlet and inlet temperature of steam, respectively.

Equation (2) is used to calculate the logarithmic mean temperature difference $\left(\Delta T_{\mathrm{lm}}\right)$ to use in estimating the true temperature difference in equation (3) by applying a correction factor $\left(F_{\mathrm{t}}\right)$ in the design of shell and tube 


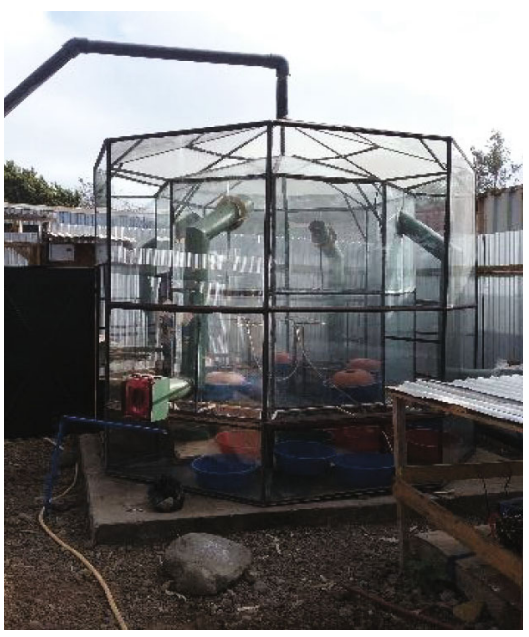

(a)

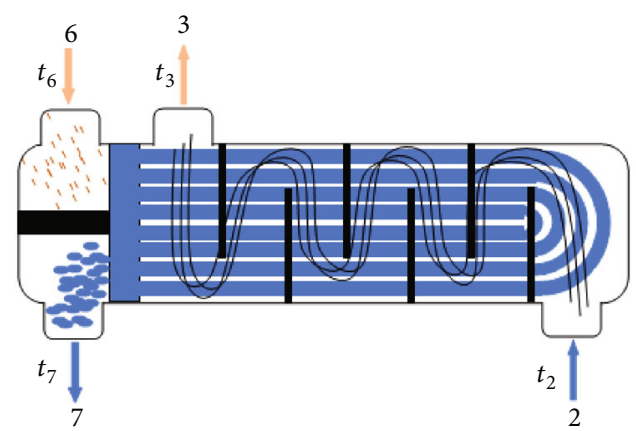

(2) cold fluid inlet (6) hot fluid inlet

(3) cold fluid outlet (7) hot fluid outlet

(b)

FIgure 3: (a) Low-temperature evaporator in Arusha Technical College, Tanzania. (b) Shell-and-tube heat exchanger model.

TABLE 1: Physical parameters of steam and water were taken from the steam evaporator.

\begin{tabular}{lcccccccc}
\hline System components & $\begin{array}{c}\dot{m} \\
(\mathrm{~kg} / \mathrm{s})\end{array}$ & $\begin{array}{c}T_{\text {inlet }} \\
\left({ }^{\circ} \mathrm{C}\right)\end{array}$ & $\begin{array}{c}T_{\text {outlet }} \\
\left({ }^{\circ} \mathrm{C}\right)\end{array}$ & $\begin{array}{c}\rho \\
\left(\mathrm{kg} / \mathrm{m}^{3}\right)\end{array}$ & $\begin{array}{c}\mathrm{Cp} \\
(\mathrm{kJ} / \mathrm{kg} \mathrm{K})\end{array}$ & $\begin{array}{c}\mu \\
(\mathrm{Pa} \mathrm{s})\end{array}$ & $\begin{array}{c}k \\
(\mathrm{~W} / \mathrm{m} \mathrm{K})\end{array}$ & $\begin{array}{c}R_{\mathrm{fouling}} \\
\left(\mathrm{m}^{2} \mathrm{~K} / \mathrm{W}\right)\end{array}$ \\
\hline Steam & 0.024 & 60 & 29 & 0.191 & 1914 & 0.000011 & 0.023 \\
Water & $0.1-0.8$ & 25 & 28 & 996.4 & 4179 & 0.00089 & 0.00009 \\
\hline
\end{tabular}

exchangers to allow for the departure from the true countercurrent flow:

$$
\begin{aligned}
& \Delta T_{\mathrm{lm}}=\frac{\left(t_{6}-t_{3}\right)-\left(t_{7}-t_{2}\right)}{\ln \left(\left(t_{6}-t_{3}\right) /\left(t_{7}-t_{2}\right)\right)}, \\
& \Delta T_{\mathrm{m}}=F_{\mathrm{t}} \Delta T_{\mathrm{lm}} .
\end{aligned}
$$

4.2. Overall Heat Transfer Coefficient Assessment. To attain a preliminary appraisal for the size of the STHX, an approximate value for the overall heat transfer coefficient $\left(U_{\mathrm{o}}\right)$ is used. According to the working fluid, the range is 1500 $4000 \mathrm{~W} / \mathrm{m}^{2} \mathrm{~K}$ as stated by [26]

$$
A=\frac{Q}{U_{\mathrm{o}} \Delta T_{\mathrm{m}}}
$$

where $A$ is the heat transfer area, $Q$ is the heat transfer rate, $U_{\mathrm{o}}$ is the pilot overall heat transfer coefficient, and $\Delta T_{\mathrm{m}}$ is the true temperature difference.

4.3. Tube-Side Calculations. From the standard tube layouts, the empirical equation (6) was used to determine bundle diameter. $n_{1}$ and $K_{1}$ in the equation are coefficients determined by the tube layout and the number of tube passes from Table 2 for triangular pitch and square pitch, while the num-

\begin{tabular}{|c|c|c|c|c|c|}
\hline Tube passes & 1 & 2 & 4 & 6 & 8 \\
\hline \multicolumn{6}{|l|}{ Square pitch } \\
\hline$n_{1}$ & 2.207 & 2.291 & 2.263 & 2.617 & 2.643 \\
\hline$K_{1}$ & 0.215 & 0.156 & 0.158 & 0.0402 & 0.0331 \\
\hline \multicolumn{6}{|c|}{ Triangular pitch } \\
\hline$n_{1}$ & 2.142 & 2.207 & 2.285 & 2.499 & 2.675 \\
\hline$K_{1}$ & 0.319 & 0.249 & 0.175 & 0.0743 & 0.0365 \\
\hline
\end{tabular}
ber of tubes $\left(n_{\mathrm{t}}\right)$ was calculated by dividing the total heat
TABLE 2: Coefficients $n_{1}$ and $K_{1}$ for use in equation (10) [27].

transfer area $(A)$ and the tube outer surface area $\left(A_{\mathrm{t}}\right)$ as shown in

$$
\begin{aligned}
& n_{\mathrm{t}}=\frac{A}{A_{\mathrm{t}}}, \\
& D_{\mathrm{b}}=d_{\mathrm{o}}\left(\frac{n_{\mathrm{t}}}{K_{1}}\right)^{1 / n_{1}} .
\end{aligned}
$$

The heat transfer coefficient $\left(h_{\mathrm{t}}\right)$ of the hot fluid stream was determined by using equation (7) [28]. It is a function of a tube inner diameter $\left(d_{\mathrm{i}}\right)$, tube side Prandtl number $\left(\mathrm{Pr}_{t}\right)$, and tube side Reynolds number $\left(\mathrm{Re}_{t}\right)$. Also, nondimensional numbers like hot fluid thermal conductivity $\left(k_{\mathrm{g}}\right)$, hot 
fluid viscosity $\left(\mu_{\mathrm{g}}\right)$, and water viscosity $\left(\mu_{\mathrm{w}}\right)$ are included in the equation [29].

$$
h_{\mathrm{t}}=\frac{k_{\mathrm{g}}}{d_{\mathrm{i}}} \operatorname{Re}_{\mathrm{t}}^{0.8} \operatorname{Pr}_{\mathrm{t}}^{0.33}\left(\frac{\mu_{\mathrm{g}}}{\mu_{\mathrm{w}}}\right)^{0.14} \text {. }
$$

4.4. Shell-Side Equations. The shell diameter is calculated as follows:

$$
\begin{aligned}
& D_{\mathrm{s}}=D_{\mathrm{c}}+D_{\mathrm{b}}, \\
& D_{\mathrm{c}}=c_{1}+m_{1} D_{\mathrm{b}} .
\end{aligned}
$$

In the above equations, $D_{\mathrm{s}}$ is a shell diameter and $D_{\mathrm{c}}$ is a clearance between the diameter of the shell and a tube bundle diameter $D_{\mathrm{b}}$, where the values of $c_{1}$ and $m_{1}$ are presented in Table 3. $c_{1}$ and $m_{1}$ are empirical coefficients that relate to the head type designed in the STHX.

The heat transfer coefficient $\left(h_{\mathrm{s}}\right)$ on the shell side was determined from equation (10), where $k_{\mathrm{f}}$ is a cold fluid thermal conductivity, $d_{\mathrm{e}}$ is a shell equivalent diameter, $J_{\mathrm{h}}$ is a Colburn factor, $\operatorname{Pr}_{\mathrm{s}}$ is a shell side Prandtl number, and $\mu_{\mathrm{f}}$ and $\mu_{\mathrm{w}}$ are cold fluid and water viscosity, respectively.

$$
h_{\mathrm{s}}=\frac{k_{\mathrm{f}}}{d_{\mathrm{e}}} J_{\mathrm{h}} \operatorname{Pr}_{\mathrm{s}}^{0.33}\left(\frac{\mu_{\mathrm{f}}}{\mu_{\mathrm{w}}}\right)^{0.14}
$$

4.5. Overall Coefficient Calculations. In this, the required overall heat transfer coefficient $U_{\text {req }}$ was calculated using

$$
U_{\text {req }}=\frac{Q}{\pi n_{\mathrm{t}} d_{\mathrm{o}} l_{\mathrm{t}} \Delta T_{\mathrm{m}}} .
$$

The clean overall heat transfer coefficient $U_{c}$ was calculated using

$$
U_{\mathrm{c}}=\left(\frac{d_{\mathrm{o}}}{h_{\mathrm{t}} d_{\mathrm{i}}}+\frac{d_{\mathrm{o}} \ln \left(d_{\mathrm{o}} / d_{\mathrm{i}}\right)}{2 k}+\frac{1}{h_{\mathrm{s}}}\right)^{-1} .
$$

If $U_{\text {req }}<U_{c}$, the following step was considered.

Then, the design overall heat transfer coefficient was determined through

$$
U_{\mathrm{d}}=\left(\frac{d_{\mathrm{o}}}{h_{\mathrm{t}} d_{\mathrm{i}}}+\frac{d_{\mathrm{o}} \ln \left(d_{\mathrm{o}} / d_{\mathrm{i}}\right)}{2 k}+\frac{1}{h_{\mathrm{s}}}+\frac{R_{\mathrm{v}} d_{\mathrm{o}}}{d_{\mathrm{i}}}+R_{\mathrm{f}}\right)^{-1} .
$$

If $U_{\mathrm{d}} \geq U_{\text {req }}$, the next step was worthy to be carried out.

Overdesign is computed in equation (14). The final design safety margin is provided by overdesign in which the required fouling compensation is represented. Oversurface deals with exchanger surface area and depends on the wall and film resistances and fouling allowance; it can be obtained through equation (15).

$$
O_{\text {des }}=\frac{U_{\mathrm{d}}}{U_{\text {req }}}-1
$$

TABLE 3: Coefficients $c_{1}$ and $m_{1}$ for use in equation (9) [30].

\begin{tabular}{lcc}
\hline Head type & $c_{1}$ & $m_{1}$ \\
\hline Outside packed head & 0.038 & 0.0 \\
Pull through floating head & 0.0862 & 0.009 \\
Split ring floating head & 0.0446 & 0.027 \\
U-tube or fixed head & 0.008 & 0.01 \\
\hline
\end{tabular}

$$
O_{\text {sur }}=\frac{U_{c}}{U_{\text {req }}}-1 .
$$

\subsection{Pressure Drop Calculations}

4.6.1. Tube-Side Pressure Drop. A pressure drop $\left(\Delta P_{\mathrm{i}}\right)$ of the hot fluid stream was computed as shown in equation (16), where $f_{\mathrm{t}}$ is a Darcy friction factor, $s_{\mathrm{t}}$ is the specific gravity in the tube side, $l_{\mathrm{t}}$ is the tube length, $G_{\mathrm{g}}$ is the hot fluid mass velocity, $n_{\mathrm{p}}$ is the number of tube passes, and $d_{\mathrm{i}}$ is the tube internal diameter.

$$
\Delta P_{\mathrm{i}}=\frac{f_{\mathrm{t}} l_{\mathrm{t}} G_{\mathrm{g}}^{2} n_{\mathrm{p}}}{7.5 \times 10^{12} d_{\mathrm{i}} s_{\mathrm{t}}} .
$$

The tube entrance, exit, and return losses can be computed through

$$
\Delta P_{\mathrm{r}}=1.334 \times 10^{-13}\left(2 n_{\mathrm{p}}-1.5\right) \frac{G_{\mathrm{g}}}{s_{\mathrm{t}}} .
$$

The pressure loss $\left(\Delta P_{\mathrm{nt}}\right)$ in the tube side nozzles is considered through equation (18), where $G_{n t}$ is a tube side nozzle mass velocity and $n_{\mathrm{s}}$ is the number of tube passes.

$$
\Delta P_{\mathrm{nt}}=2.0 \times 10^{-13} \frac{n_{\mathrm{s}} G_{\mathrm{nt}}^{2}}{s_{\mathrm{t}}}
$$

Equation (19) was used to evaluate the total pressure drop $\left(\Delta P_{\mathrm{t}}\right)$ across the hot fluid stream on the tube side as presented below:

$$
\Delta P_{\mathrm{t}}=\Delta P_{\mathrm{i}}+\Delta P_{\mathrm{r}}+\Delta P_{\mathrm{nt}}
$$

4.6.2. Shell-Side Pressure Drop. Equation (20) was used to find the initial shell side pressure losses $\left(\Delta P_{\mathrm{o}}\right)$, where $s_{\mathrm{s}}$ is a specific gravity in the shell side, $f_{\mathrm{s}}$ is the friction factor, $d_{\mathrm{e}}$ is the equivalent diameter, $n_{\mathrm{b}}$ is the number of the baffle, and $D_{s}$ is a shell diameter.

$$
\Delta P_{\mathrm{o}}=\frac{f_{\mathrm{s}}\left(G_{\mathrm{g}}\right)^{2} D_{\mathrm{s}}\left(n_{\mathrm{b}}+1\right)}{7.5 \times 10^{12} d_{\mathrm{e}} s_{\mathrm{s}}} .
$$




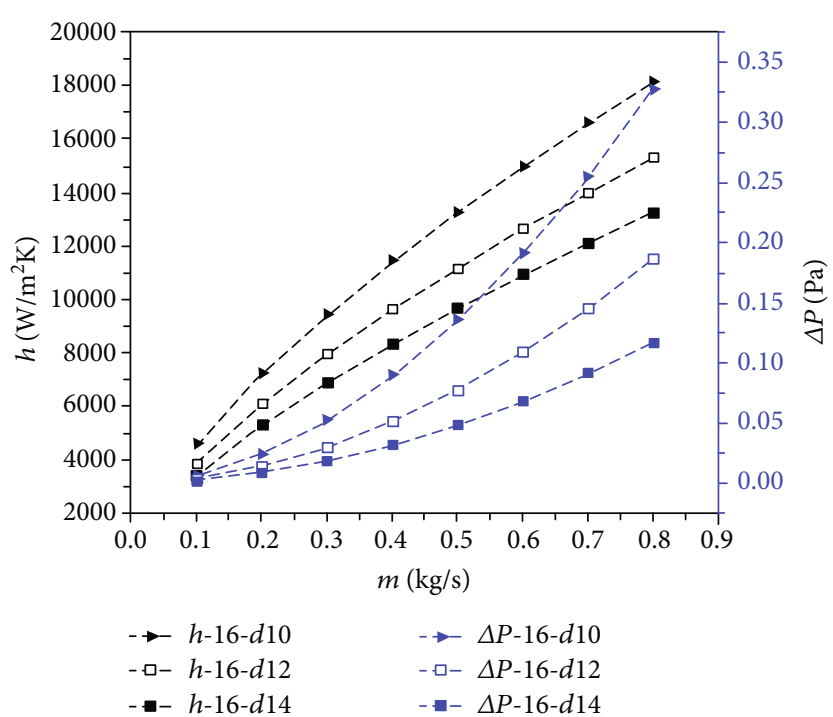

(a)

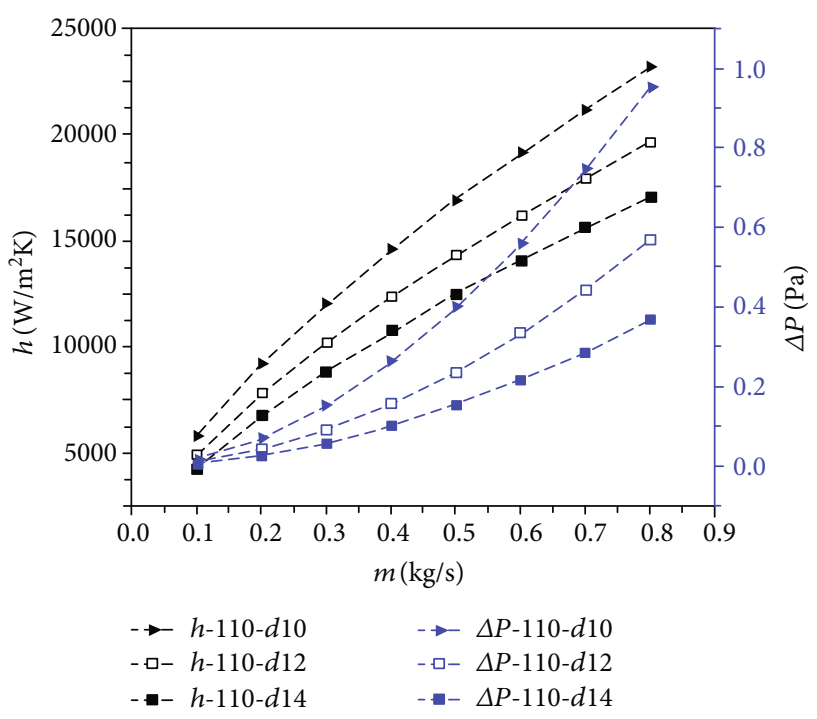

(c)

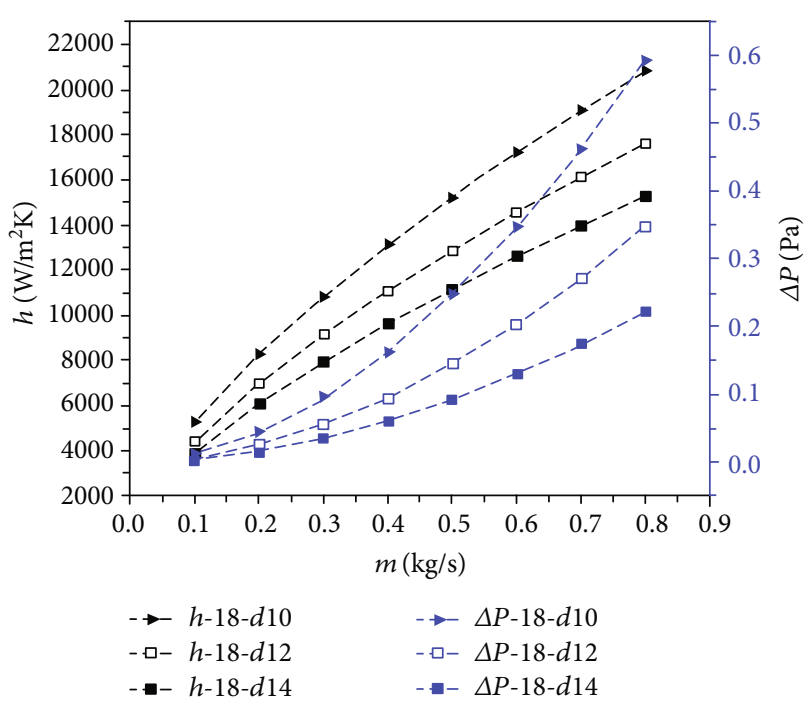

(b)

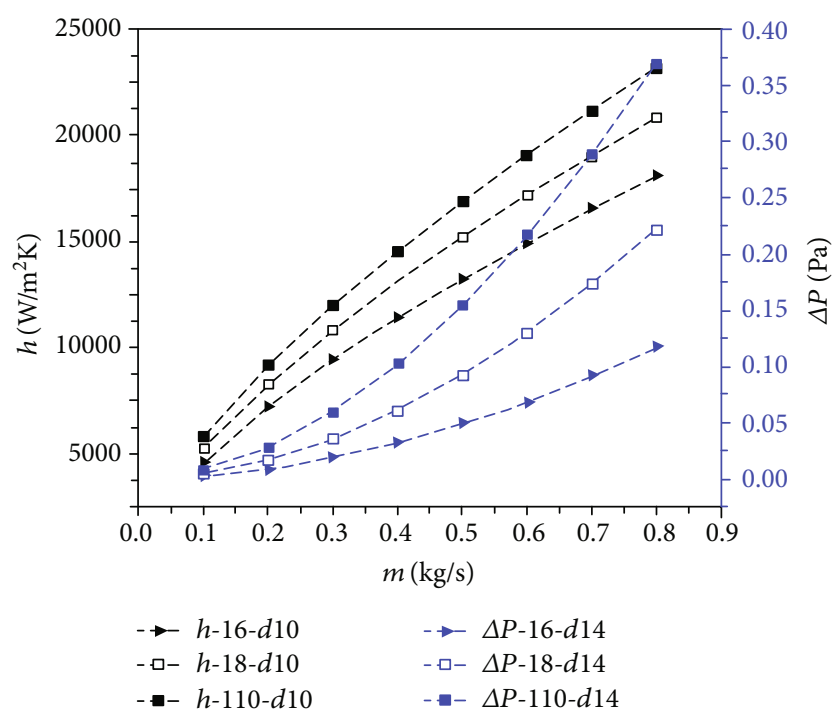

(d)

Figure 4: Pressure drop and heat transfer coefficient versus mass flow rate: (a) $600 \mathrm{~mm}$ length, (b) $1000 \mathrm{~mm}$ length, (c) $800 \mathrm{~mm}$ length, and (d) maximum heat transfer coefficient and minimum pressure drop among all configurations.

Also, the pressure loss in the shell side nozzles $\left(\Delta P_{\mathrm{ns}}\right)$ was considered through equation (21), where $G_{\mathrm{ns}}$ is a shell side nozzle mass velocity and $n_{\mathrm{s}}$ is the number of tube passes.

$$
\Delta P_{\mathrm{ns}}=2.0 \times 10^{-13} \frac{n_{\mathrm{s}} G_{\mathrm{ns}}^{2}}{s_{\mathrm{s}}} .
$$

Then, the net pressure drop $\left(\Delta P_{s}\right)$ across the cold fluid stream on the shell side should be computed by summing the nozzle pressure loss and initial shell side pressure losses as per

$$
\Delta P_{\mathrm{s}}=\Delta P_{\mathrm{o}}+\Delta P_{\mathrm{ns}}
$$

\section{Results and Discussion}

5.1. Effect on the Pressure Drop and the Heat Transfer Coefficient. Figures 4(a)-4(c) show the pressure drop together with heat transfer coefficient variations within the STHX with the length of $600 \mathrm{~mm}, 800 \mathrm{~mm}$, and $1000 \mathrm{~mm}$ for three different tube outer diameters of $10 \mathrm{~mm}, 12 \mathrm{~mm}$, and $14 \mathrm{~mm}$ with $1 \mathrm{~mm}$ thick for each, respectively, through a given range of mass flow of $0.1-0.8 \mathrm{~kg} / \mathrm{s}$ as regards the shell side. From Figures 4(a)-4(c), it can be seen that both the heat transfer coefficient and the pressure drop increase proportionally to the mass flow rate by considering the nine configurations of heat exchangers. Also, confirm that the heat transfer coefficient is much greater at any point in the range of mass flow rate compared to the pressure drop. Hence, it is noted that the diameter of $10 \mathrm{~mm}$ shows the greatest heat 


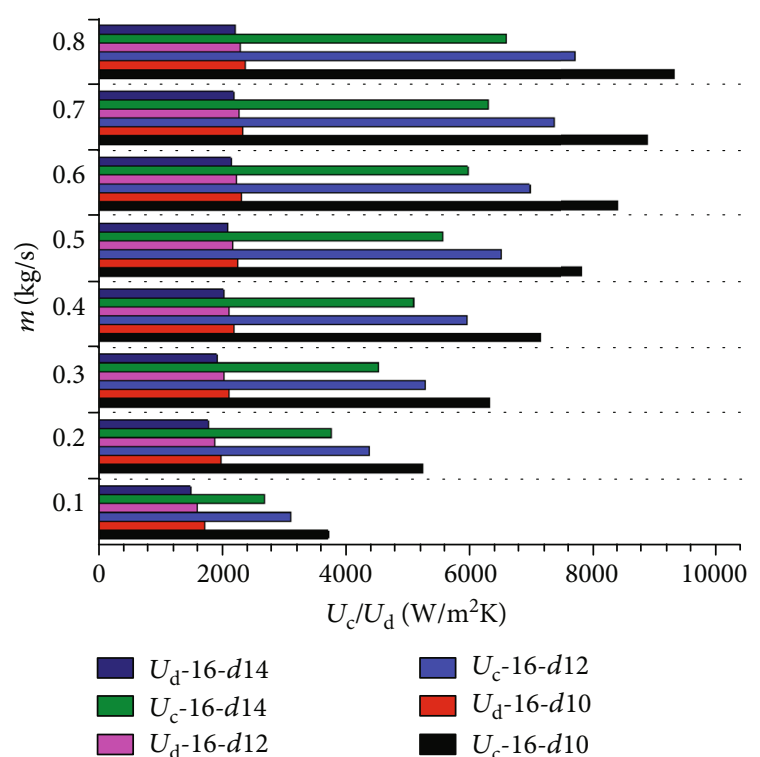

(a)

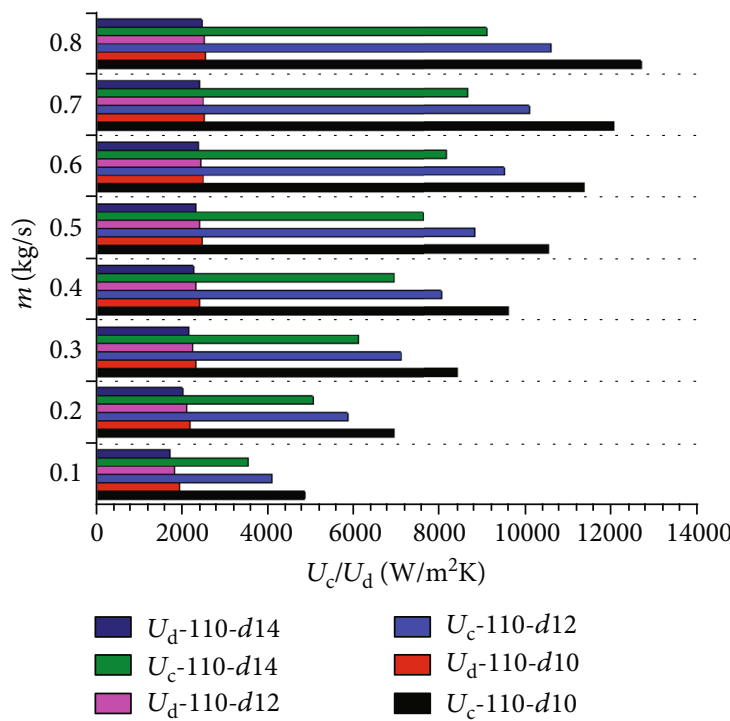

(c)

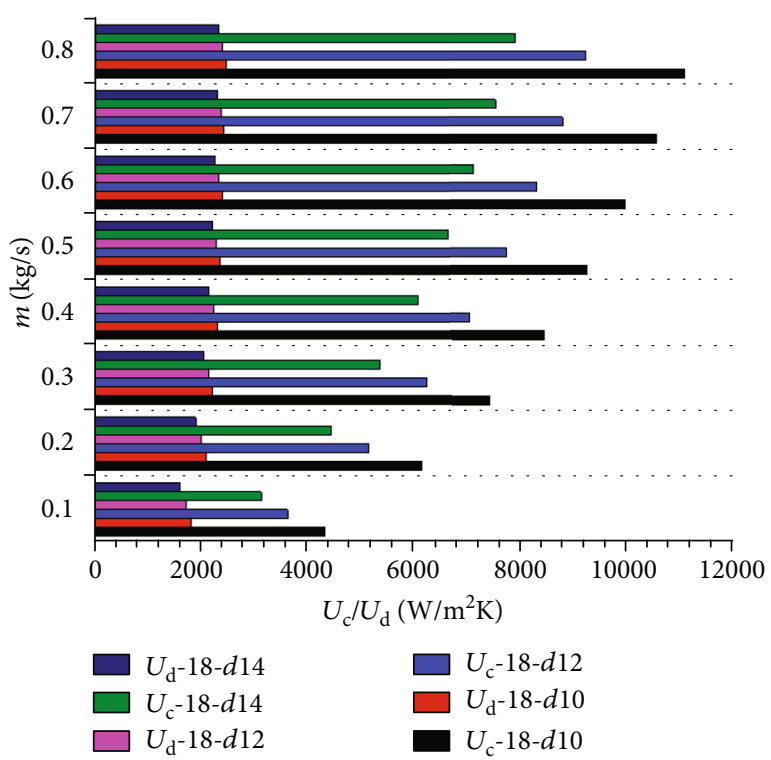

(b)

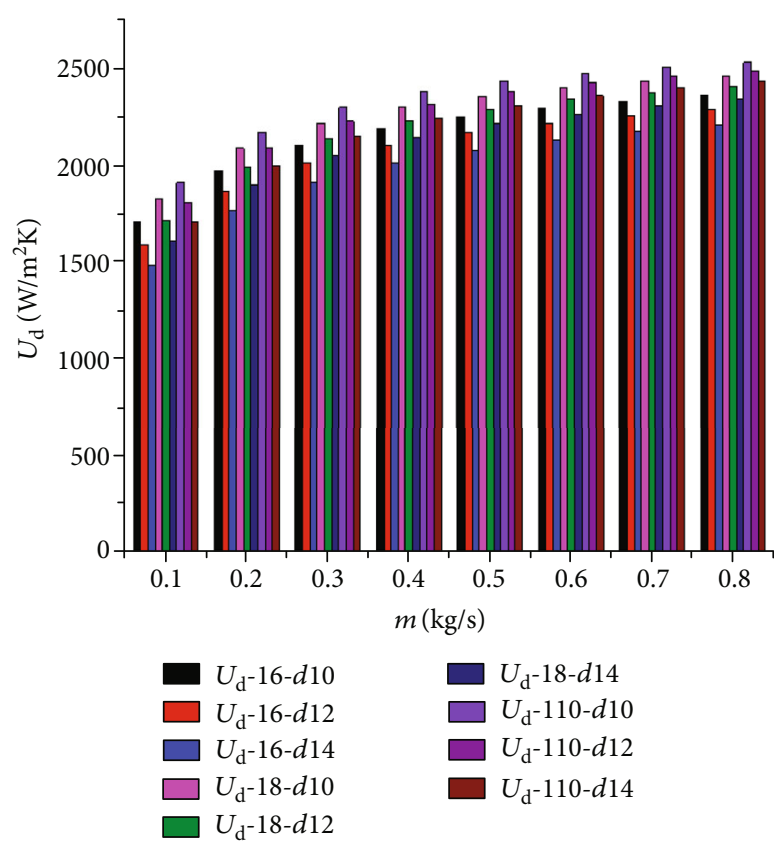

(d)

Figure 5: Overall heat transfer coefficient versus mass flow rate: (a) $600 \mathrm{~mm}$ length, (b) $800 \mathrm{~mm}$ length, (c) $1000 \mathrm{~mm}$ length, and (d) design overall heat transfer coefficient among all configurations.

transfer coefficient of 18162,20881 , and $23212 \mathrm{~W} / \mathrm{m}^{2} \mathrm{~K}$ and the maximum pressure drop of $0.328,0.593$, and $0.957 \mathrm{~Pa}$, while the diameter of $14 \mathrm{~mm}$ shows a minimum pressure drop of $0.117,0.223$, and $0.370 \mathrm{~Pa}$ and a lesser heat transfer coefficient of 13265,15326 , and $17107 \mathrm{~W} / \mathrm{m}^{2} \mathrm{~K}$ in the length of $600 \mathrm{~mm}, 800 \mathrm{~mm}$, and $1000 \mathrm{~mm}$, respectively.

Figure 4(d) illustrates the variation of all minimum pressure drop (blue) which appears in the tube with a diameter of $14 \mathrm{~mm}$ versus the cold fluid stream mass flow rate in the shell side for the three different tube length exchangers. The results show that the tube configuration with a minimum length $(600 \mathrm{~mm})$ has a minimum pressure drop of $0.117 \mathrm{~Pa}$ corresponding to the rest of the configurations. Figure 4(d) also shows the results of the variation of the maximum heat transfer coefficient (black) which appears in the tube with a diameter of $10 \mathrm{~mm}$ versus cold stream mass flow rate in the shell side for the three different tube length exchangers; thus, the tube configuration with a maximum length of $1000 \mathrm{~mm}$ portrays maximum heat transfer coefficient of $23212 \mathrm{~W} / \mathrm{m}^{2} \mathrm{~K}$ compared to the rest of the configurations.

5.2. Effect on the Overall Heat Transfer Coefficient. Figures 5(a)-5(c)) express the effect of mass flow rate on the overall heat transfer coefficients of design heat transfer 


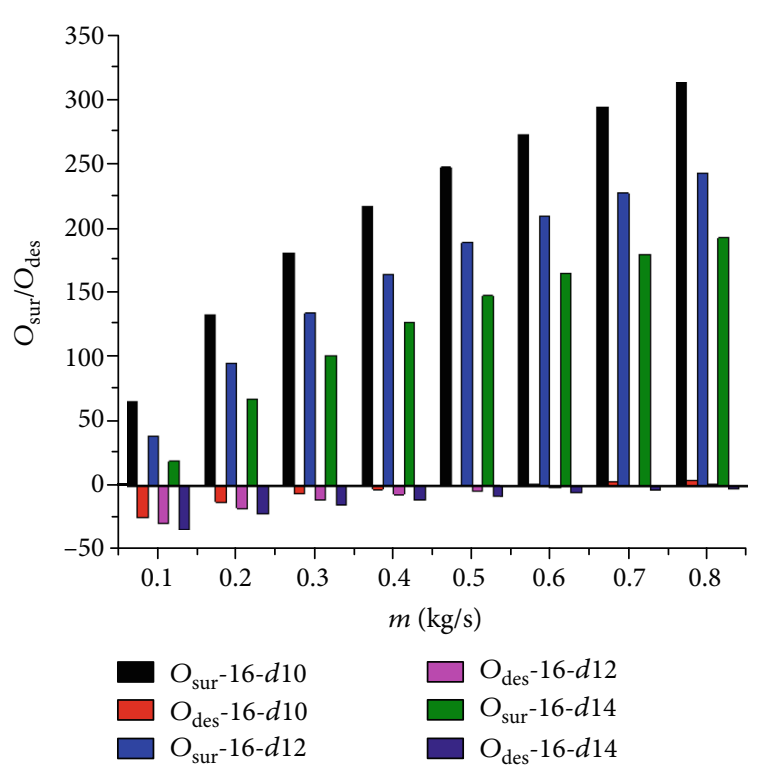

(a)

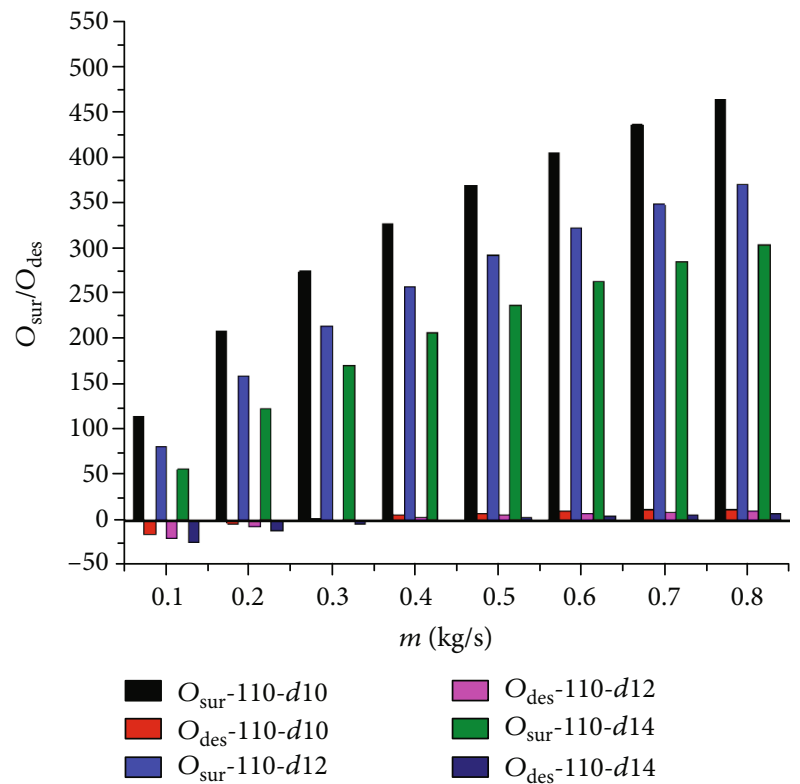

(c)

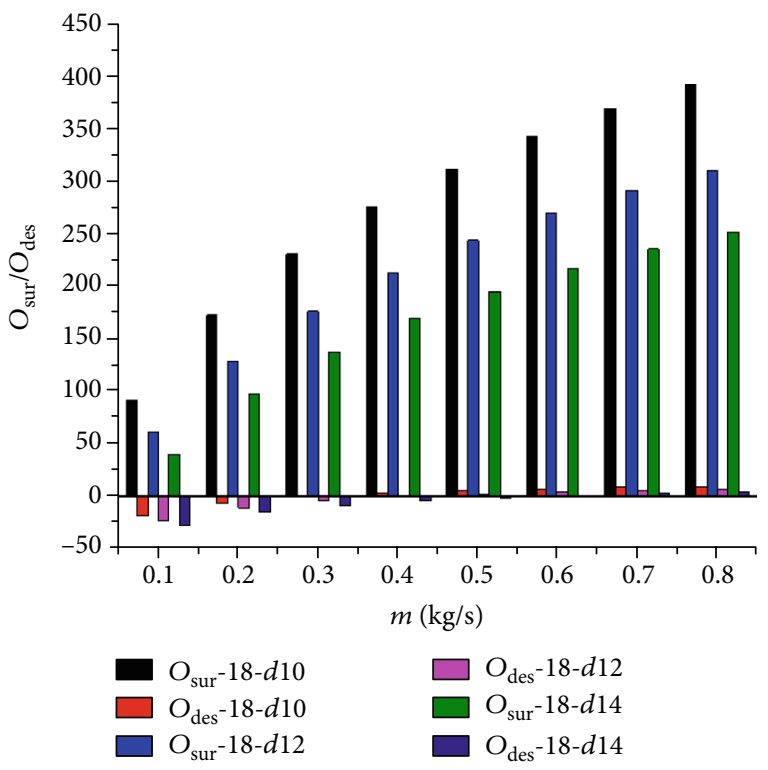

(b)

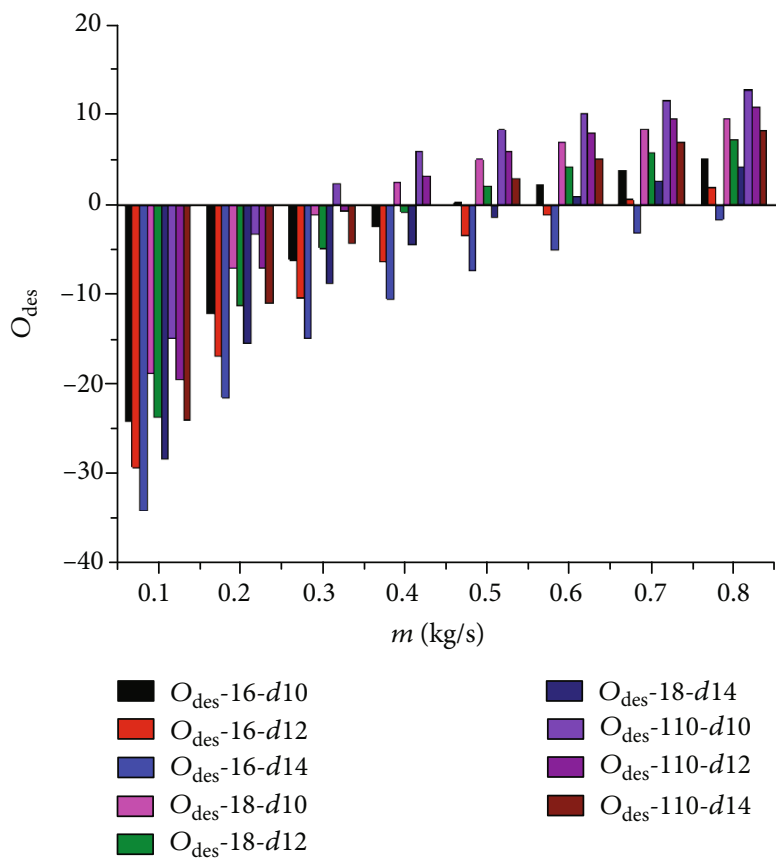

(d)

FIGURE 6: Oversurface and overdesign versus mass flow rate: (a) $600 \mathrm{~mm}$ length, (b) $800 \mathrm{~mm}$ length, (c) $1000 \mathrm{~mm}$ length, and (d) overdesign among all configurations.

coefficient $\left(U_{\mathrm{d}}\right)$ and clean heat transfer coefficient $\left(U_{\mathrm{c}}\right)$ within the STHX with the length of $600 \mathrm{~mm}, 800 \mathrm{~mm}$, and $1000 \mathrm{~mm}$ for three different tube outer diameters of $10 \mathrm{~mm}$, $12 \mathrm{~mm}$, and $14 \mathrm{~mm}$, respectively, with $1 \mathrm{~mm}$ thick for each. The results for both $U_{\mathrm{d}}$ and $U_{\mathrm{c}}$ coefficients demonstrate that when the cold fluid flows over the whole surface of the shell were varied, $U_{\mathrm{d}}$ and $U_{c}$ increase constantly at any rate regardless of the difference in the tube configuration throughout the study. On the other hand, $U_{c}$ is shown to increase twice or more than $U_{\mathrm{d}}$ when there is an increase in mass flow in the shell side. This is due to the significant effect of the fouling factor of the working fluids. However, the increase in mass flow and sustaining the temperatures keep $U_{\mathrm{d}}$ and $U_{\mathrm{c}}$ rising proportionally; the design coefficient is used rather than the clean coefficient based on the interest of overdesign. The highest and smallest values of $U_{\mathrm{d}}$ appeared in 10 and $14 \mathrm{~mm}$ tube diameter, respectively.

Figure 5(d) illustrates $U_{\mathrm{d}}$ which appears through all-tube configurations. The result shows that the tube configuration with a maximum length $(1000 \mathrm{~mm})$ has maximum $U_{\mathrm{d}}$ compared to the other configurations. Moreover, it can be seen that as the length of the tube increases with a decrease in 
diameter the maximum $U_{\mathrm{d}}$ is achieved. To provide the required rate of heat transfer, the value of $U_{\mathrm{d}}$ should be greater than or equal to the value of the required coefficient, $U_{\text {req }}$. The results show that the suitable mass flow of 0.3$0.8 \mathrm{~kg} / \mathrm{s}$ with a range of $2306-2539 \mathrm{~W} / \mathrm{m}^{2} \mathrm{~K}$ can be selected for the proper design of the exchanger as shown in Figure 6(d).

5.3. Effect on the Oversurface and Overdesign. Figures 6(a)$6(\mathrm{c})$ demonstrate the oversurface $\left(O_{\text {sur }}\right)$ and overdesign $\left(O_{\text {des }}\right)$ changes when designing the STHX with the length of $600 \mathrm{~mm}, 800 \mathrm{~mm}$, and $1000 \mathrm{~mm}$ for three different tube outer diameters of $10 \mathrm{~mm}, 12 \mathrm{~mm}$, and $14 \mathrm{~mm}$ with $1 \mathrm{~mm}$ thick for each, respectively, through a given range of $0.1-0.8 \mathrm{~kg} / \mathrm{s}$. Since $U_{\text {req }}$ is much smaller than $U_{c}, O_{\text {sur }}$ appeared to increase in the range of 19.2-463.3 as the mass flow increases. $O_{\text {des }}$ were shown to increase slightly from negative value on $0.1-0.3 \mathrm{~kg} / \mathrm{s}$ to a positive value on $0.4-0.8 \mathrm{~kg} / \mathrm{s}$ in a range of $-33.9-12.8$.

Since engineers do recognize that there will be uncertainties on the data provided and that there may be times when the feedstock will not exactly match up to what was originally specified, a certain amount of conservatism will be required just to achieve satisfactory performance despite unforeseen circumstances. Figure 6(d) clarifies the possibility of designing the suitable STHX by displaying the greatest values of $O_{\text {des }}$ which mostly appeared in the smallest tube diameter $(10 \mathrm{~mm})$ to all three tube length configurations with a total of nine samples. However, $O_{\text {des }}$ is a negative value at a low mass flow rate of $0.1-0.3 \mathrm{~kg} / \mathrm{s}$ specifically to the configurations of length $600 \mathrm{~mm}$ and $800 \mathrm{~mm}$. Conversely, as mass flow increases from 0.4 to $0.8 \mathrm{~kg} / \mathrm{s}, O_{\text {des }}$ becomes a positive value. Hereafter, the configuration with tube length $1000 \mathrm{~mm}$ performed well even from the mass flow of $0.3 \mathrm{~kg} / \mathrm{s} \mathrm{compared}$ to other configurations.

\section{Conclusion}

A heat exchanger model for a low-temperature desalination system was established through the influence tube length and diameter, mass flow rate on pressure drop, heat transfer coefficient, overall heat transfer coefficient, oversurface, and overdesign. After making a deep analysis of these heat transfer parameters, the following summarized conclusions were obtained.

(i) Both the heat transfer coefficient and the pressure drop increase proportionally to the mass flow rate among all nine configurations of heat exchangers. But the pressure drop is noticed to be very low 0.328-0.957 $\mathrm{Pa}$ for all studied configurations that will lower the pumping power

(ii) The clean overall heat transfer coefficient increases twice or more to that of the design coefficient when there is an increase in mass flow in the shell side due to the effect of the fouling factor

(iii) The maximum design coefficient is achieved by increasing the tube length with a decrease in diameter. Also, the mass flow of $0.3-0.8 \mathrm{~kg} / \mathrm{s}$ is suitable for the proper design of exchanger in the present study

(iv) The configuration with the $1000 \mathrm{~mm}$ length and $10 \mathrm{~mm}$ diameter which provides high heat transfer is recommended to work with a maximum flow rate of $0.8 \mathrm{~kg} / \mathrm{s}$ to achieve a maximum heat transfer coefficient of $23212 \mathrm{~W} / \mathrm{m}^{2} \mathrm{~K}$, while 12.8 is a maximum overdesign coefficient achieved on $0.8 \mathrm{~kg} / \mathrm{s}$ mass flow

(v) Therefore, the implementation of the proposed layout will ensure less energy consumption in the system. Hence, an experimental study is recommended to be done to compare the results obtained by the present mathematical model

\section{Nomenclature}

A: $\quad$ Area $\left(\mathrm{m}^{2}\right)$

Cp: Specific heat capacity $(\mathrm{kJ} / \mathrm{kg})$

$D, d$ : Diameter (m)

$\dot{m}$ : Mass flow rate $(\mathrm{kg} / \mathrm{s})$

$n$ : $\quad$ Pass number, number

$F_{\mathrm{t}}: \quad$ Correction factor

$f_{t}:$ Darcy friction factor

G: $\quad$ Mass velocity $\left(\mathrm{kg} / \mathrm{s} \mathrm{m}^{2}\right)$

$h$ : Heat transfer coefficient $\left(\mathrm{W} / \mathrm{m}^{2} \mathrm{~K}\right)$

$k: \quad$ Thermal conductivity $(\mathrm{W} / \mathrm{m} \mathrm{K})$

Q: $\quad$ Heat load $(\mathrm{kW})$

$t$ : $\quad$ Temperature $\left({ }^{\circ} \mathrm{C}\right)$

$s: \quad$ Specific gravity

$U: \quad$ Overall heat transfer coefficient $\left(\mathrm{W} / \mathrm{m}^{2} \mathrm{~K}\right)$

Pr: Prandtl number

Re: Reynolds number.

Greek Letters

$\mu: \quad$ Viscosity $(\mathrm{kg} / \mathrm{m} \mathrm{s})$

$\rho: \quad$ Density $\left(\mathrm{kg} / \mathrm{m}^{3}\right)$

$\Delta P:$ Pressure drop $(\mathrm{Pa})$

$\Delta T$ : Temperature difference (K).

\section{Subscripts}

6: Hot fluid inlet

7: Hot fluid outlet

2: Cold fluid inlet

3: Cold fluid outlet

b: Baffle

c: Clearance, clean

d: Design

e: Equivalent

f: Liquid, cold fluid

t: Tube

g: Vapor, gas, steam

w: Water

i: Initial, inner

r: Return

req: Required

lm: Logarithmic mean 
$\begin{array}{ll}\mathrm{n}: & \text { Nozzles } \\ \mathrm{m}: & \text { Material, mean } \\ \mathrm{s}: & \text { Shell } \\ \mathrm{o}: & \text { Outer. }\end{array}$

Abbreviations

STHX: Shell-and-tube heat exchanger.

\section{Data Availability}

The data used to support the findings of this study are available from the corresponding author upon request.

\section{Conflicts of Interest}

There are no conflicts to declare.

\section{Acknowledgments}

The authors would like to acknowledge the Arusha Technical College for allowing performing this study.

\section{References}

[1] Q. Chen, M. Kum Ja, Y. Li, and K. J. Chua, "Evaluation of a solar-powered spray-assisted low-temperature desalination technology," Applied Energy, vol. 211, pp. 997-1008, 2018.

[2] M. Maria Antony Raj, K. Kalidasa Murugavel, T. Rajaseenivasan, and K. Srithar, "A review on flash evaporation desalination," Desalination and Water Treatment, vol. 57, no. 29, pp. 1346213471, 2015.

[3] Q. Chen, M. K. Ja, Y. Li, and K. J. Chua, "Energy, economic and environmental (3E) analysis and multi-objective optimization of a spray-assisted low-temperature desalination system," Energy, vol. 151, pp. 387-401, 2018.

[4] V. G. Gude and N. Nirmalakhandan, "Desalination at low temperatures and low pressures," Desalination, vol. 244, no. 1-3, pp. 239-247, 2009.

[5] S. Al-Kharabsheh and D. Yogi, "Analysis of an innovative water desalination system using low-grade solar heat," Desalination, vol. 156, no. 1-3, pp. 323-332, 2003.

[6] R. Roy, "Optimization of design parameters on shell and tube heat exchangers using flower pollination algorithm based on economic dispatch," International Journal for Emerging Research and Development, vol. 1, no. 5, pp. 11-15, 2018.

[7] S. M. Alsadaie and I. M. Mujtaba, "Dynamic modelling of heat exchanger fouling in multistage flash (MSF) desalination," Desalination, vol. 409, pp. 47-65, 2017.

[8] B. Ghorbani, R. Shirmohammadi, M. Amidpour, F. Inzoli, and M. Rocco, "Design and thermoeconomic analysis of a multi-effect desalination unit equipped with a cryogenic refrigeration system," Energy Conversion and Management, vol. 202, p. 112208, 2019.

[9] E. Elsayed, R. al-Dadah, S. Mahmoud, P. Anderson, and A. Elsayed, "Experimental testing of aluminium fumarate MOF for adsorption desalination," Desalination, vol. 475, p. 114170, 2020.

[10] C. Olkis, S. Brandani, and G. Santori, "Cycle and performance analysis of a small-scale adsorption heat transformer for desalination and cooling applications," Chemical Engineering Journal, vol. 378, p. 122104, 2019.
[11] K. Thu, Y. D. Kim, A. Myat, A. Chakraborty, and K. C. Ng, "Performance investigation of advanced adsorption desalination cycle with condenser-evaporator heat recovery scheme," Desalination and Water Treatment, vol. 51, no. 1-3, pp. 150163, 2012.

[12] H. Rezk, A. S. Alsaman, M. al-Dhaifallah, A. A. Askalany, M. A. Abdelkareem, and A. M. Nassef, "Identifying optimal operating conditions of solar-driven silica gel based adsorption desalination cooling system via modern optimization," Solar Energy, vol. 181, pp. 475-489, 2019.

[13] S.-Y. Woo, H. S. Lee, H. Ji, D. S. Moon, and Y. D. Kim, "Silica gel-based adsorption cooling cum desalination system: focus on brine salinity, operating pressure, and its effect on performance," Desalination, vol. 467, pp. 136-146, 2019.

[14] A. David, R. K. Sinha, and J. M. Paul, "Feasibility of working of evaporative condenser cum thermal desalination system," International Journal of Innovative Research in Technology, vol. 5, no. 8, pp. 79-82, 2019.

[15] K. Rabhi, R. Nciri, F. Nasri, C. Ali, and H. Ben Bacha, "Experimental performance analysis of a modified single-basin single-slope solar still with pin fins absorber and condenser," Desalination, vol. 416, pp. 86-93, 2017.

[16] B. Chandrakanth, G. Venkatesan, L. S. S. Prakash Kumar, P. Jalihal, and S. Iniyan, "Thermal design, rating and second law analysis of shell and tube condensers based on Taguchi optimization for waste heat recovery based thermal desalination plants," Heat and Mass Transfer, vol. 54, no. 9, pp. 2885-2897, 2018.

[17] Y. Matsuda, Y. Eishima, S. Goto et al., "Construction of water level model for after condenser in spray flash desalination system via stochastic process," in Proceedings of the 49th ISCIE International Symposium on Stochastic System Theory and Its Applications, Hiroshima, Japan, 2017.

[18] H. Xu, X. Sun, and Y. Dai, "Thermodynamic study on an enhanced humidification-dehumidification solar desalination system with weakly compressed air and internal heat recovery," Energy Conversion and Management, vol. 181, pp. 6879, 2019.

[19] S. Kakaç, H. Liu, and A. Pramuanjaroenkij, Heat exchangers: selection, rating, and thermal design, CRC press, 2002.

[20] B. Sundén and R. M. Manglik, Plate heat exchangers: design, applications and performance, vol. 11, Wit Press, 2007.

[21] A. A. A. Arani and R. Moradi, "Shell and tube heat exchanger optimization using new baffle and tube configuration," Applied Thermal Engineering, vol. 157, p. 113736, 2019.

[22] M. Nitsche and R. O. Gbadamosi, Heat exchanger design guide: a practical guide for planning, selecting and designing of shell and tube exchangers, Butterworth-Heinemann, 2015.

[23] R. Lord, P. Minton, and R. Slusser, "Design of heat exchangers," Chemical Engineer, vol. 77, no. 2, pp. 96-118, 1970.

[24] A. S. Ambekar, R. Sivakumar, N. Anantharaman, and M. Vivekenandan, "CFD simulation study of shell and tube heat exchangers with different baffle segment configurations," Applied Thermal Engineering, vol. 108, pp. 999-1007, 2016.

[25] C. Gonçalves, A. L. H. Costa, and M. J. Bagajewicz, "Linear method for the design of shell and tube heat exchangers using the Bell-Delaware method," AICHE Journal, vol. 65, no. 8, p. 8, 2019.

[26] D. Y. Goswami, The CRC Handbook of Mechanical Engineering, CRC press, 2004. 
[27] G. Towler and R. Sinnott, Chemical engineering design: principles, practice and economics of plant and process design, Elsevier, 2012.

[28] R. W. Serth and T. Lestina, Process heat transfer: principles, applications and rules of thumb, Academic press, 2014.

[29] K. Thulukkanam, Heat Exchanger Design Handbook, CRC press, 2013.

[30] N. M. Khalfe, K. S. Lahiri, and K. S. Wadhwa, "Simulated annealing technique to design minimum cost exchanger," Chemical Industry and Chemical Engineering Quarterly/CICEQ, vol. 17, no. 4, pp. 409-427, 2011. 